\title{
Superfluous Amylase/Lipase Testing at a University-Affiliated Teaching Hospital: A Retrospective Review
}

\author{
Muhammad Baraa Hammami, MD, Milad Khoury, MD, Sachin S. Sule, MD, Henry M. Haire, MD \\ Department of Internal Medicine, Florida Atlantic University, Charles E. Schmidt College of Medicine, Boca Raton Regional Hospital,
} Boca Raton, FL

\begin{abstract}
Background: The combination of amylase and lipase tests for diagnosing acute pancreatitis is not better than a lipase test alone; however, both tests are commonly ordered simultaneously. Further, although no data indicate usefulness of monitoring changes in elevated amylase and lipase levels, the tests are often ordered multiple times during the same clinical encounter.

Methods: We retrospectively reviewed all amylase and lipase tests performed at a university-affiliated teaching hospital during a 6-month period. We considered amylase and lipase results diagnostic if they were $>3$ times the upper limit of normal and borderline if they were $\leq 3$ times the upper limit of normal. During a single clinical encounter, we considered amylase tests superfluous if ordered simultaneously with lipase tests or repeated after diagnostic results, questionably superfluous if repeated alone, and nonsuperfluous otherwise. Lipase tests were considered superfluous if repeated after diagnostic results, questionably superfluous if repeated after nondiagnostic results, and nonsuperfluous otherwise.

Results: In this study, 3,502 patients had 8,801 tests (4,926 lipase, 3,875 amylase), 4\% of which were diagnostic and 10\% borderline. Of the 8,801 tests, $45 \%$ were superfluous and $9 \%$ were questionably superfluous. Nonsuperfluous testing was less frequent $(P<0.0001)$ in the intensive care/stepdown units $(22 \%$ of 748 tests) than in the emergency department $(54 \%$ of 6,000 tests) or other settings ( $31 \%$ of 2,053 tests). Among 3,545 simultaneous amylase/lipase tests with nondiagnostic lipase results, $0.6 \%$ amylase results were diagnostic. Of the 190 lipase tests repeated after nondiagnostic lipase results, $12 \%$ were diagnostic.

Conclusion: Superfluous amylase/lipase testing in one teaching hospital is substantial, suggesting significant potential for reducing healthcare costs without compromising the quality of care when evaluating patients for acute pancreatitis.
\end{abstract}

Keywords: Amylases, pancreas, pancreatitis, quality improvement

Address correspondence to Henry M. Haire, MD, Medical Director FAU Medicine Resident Clinic, Associate Professor of Integrated Medical Science, Charles E. Schmidt College of Medicine, Florida Atlantic University, 670 Glades Rd., Suite 400, Boca Raton, FL 33431. Tel: (561) 955-2570. Email: hhaire@health.fau.edu

\section{INTRODUCTION}

The diagnosis of acute pancreatitis (AP) is established by the presence of 2 of 3 criteria: characteristic abdominal pain, serum amylase and/or lipase $>3$ times the upper limit of normal, and characteristic findings on abdominal imaging. ${ }^{1}$

The sensitivity of serum amylase is limited as amylase levels may remain normal in patients with hypertriglyceridemia, alcohol-induced AP, or acute exacerbation of chronic pancreatitis. ${ }^{2-6}$ Further, several conditions may result in the elevation of amylase level, such as macroamylasemia, decreased glomerular filtration rate, diseases of the salivary glands, acute appendicitis, cholecystitis, intestinal obstruction or ischemia, peptic ulcer, and gynecologic diseases. ${ }^{1,6}$

Serum lipase may also be elevated in nonpancreatic diseases..$^{2,7-10}$ In addition, patients with diabetes tend to have higher lipase levels than patients without diabetes; therefore, a higher lipase level may be needed to estab- lish a diagnosis of AP. ${ }^{10,11}$ Nevertheless, several studies have demonstrated that serum lipase is more sensitive and just as specific a marker as serum amylase in diagnosing AP and that the combination of amylase and lipase testing is not better than lipase alone ${ }^{3,12-24}$; these findings are reflected in the 2013 guidelines of the American College of Gastroenterology. ${ }^{1}$ However, both tests are still commonly ordered simultaneously. ${ }^{25}$ Further, although several studies failed to show the prognostic usefulness of repeating amylase and lipase tests after obtaining diagnostic results, ${ }^{6,26}$ the tests are often ordered multiple times throughout the course of a single AP episode. ${ }^{27-29}$

The clinical utility of repeating amylase and lipase tests after an initially normal or borderline result is not well established. The serum amylase level tends to rise 2-4 hours after the onset of AP symptoms and returns to normal within 5-7 days. On the other hand, the serum lipase level tends to rise 
within 4-6 hours of AP symptoms and remains elevated for 8-14 days. ${ }^{30}$ Thus, during the early hours following the onset of AP symptoms, both amylase and lipase levels could conceivably remain below diagnostic thresholds.

As a first step in a quality improvement/healthcare cost reduction initiative, the primary aim of this study was to explore the extent of superfluous amylase/lipase testing at Boca Raton Regional Hospital (BRRH), a university-affiliated teaching hospital in Florida. We also assessed the frequency of obtaining diagnostic amylase results with a simultaneous normal or borderline lipase level and of obtaining diagnostic amylase or lipase results after same-clinical-encounter normal or borderline levels.

\section{METHODS}

This study was conducted in accordance with the Declaration of Helsinki after approval of the Institutional Review Board of Florida Atlantic University.

We retrospectively reviewed all amylase and lipase tests that were performed at BRRH during a 6-month period (July 3, 2017 to January 29, 2018). Locations where blood was drawn, results, times, and dates of all amylase and lipase tests performed during this period were provided to the investigators by the medical records service in a deidentified format.

Based on the laboratory reference range, lipase and amylase levels were classified as normal if they were $<393 \mathrm{U} / \mathrm{L}$ and $<105 \mathrm{IU} / \mathrm{L}$, respectively. Lipase and amylase were considered diagnostic of AP if they were $>3$ times the upper limit of normal (ie, lipase $>1,179 \mathrm{U} / \mathrm{L}$, amylase $>315 \mathrm{IU} / \mathrm{L}$ ), and results were considered borderline if levels were $\leq 3$ times the upper limit of normal (ie, lipase $>393$ but $\leq 1,179 \mathrm{U} / \mathrm{L}$, amylase $>105$ but $\leq 315$ IU/L).

Each patient was assigned a code number. Lipase and amylase tests were classified as occurring during the same or during different clinical encounters based on location and the time interval between the tests. Three main locations were identified: outpatient, emergency department (ED), and inpatient. Tests obtained in the outpatient setting were considered to belong to different clinical encounters if they were not done on the same date. Tests obtained in the ED were considered to belong to different clinical encounters if they were separated by more than 48 hours. Tests obtained in the inpatient setting were considered to belong to different clinical encounters if they were separated by tests obtained in an ED or outpatient setting. The inpatient setting was further classified into intensive care unit (ICU)/stepdown unit, regular floor, and endoscopy suite.

We considered an amylase test to be superfluous if it was performed simultaneously during the same clinical encounter with a lipase test or repeated after a diagnostic amylase test, questionably superfluous if it was repeated alone after normal or borderline amylase test, and nonsuperfluous otherwise. We considered a lipase test to be superfluous if it was repeated after a diagnostic lipase test, questionably superfluous if it was repeated after normal or borderline lipase test, and nonsuperfluous otherwise. Tests repeated during the same clinical encounter were also classified based on the immediate previous test result into repeated after normal, borderline, or diagnostic test.

We calculated the number and percentage of lipase and amylase tests per location (ICU/stepdown unit, ED, or other



Figure 1. Nonsuperfluous, superfluous, and questionably superfluous amylase and lipase tests. Bars represent number of tests ordered during a 6-month period.

settings [outpatient, regular floor, and endoscopy suite]), per level (normal, borderline, or diagnostic), and per utility (superfluous, questionably superfluous, or nonsuperfluous). Numbers of superfluous tests were compared among locations using Fisher exact test. We also calculated the number and percentage of diagnostic amylase tests that were obtained simultaneously with normal or borderline lipase tests and of diagnostic amylase or lipase results that were obtained after normal or borderline results.

\section{RESULTS}

A total of 3,502 patients had 8,801 tests $(4,926$ lipase, 3,875 amylase) during up to 10 clinical encounters.

Of the 8,801 tests, 361 (4\%) were diagnostic (5\% of 4,926 total lipase tests and $3 \%$ of 3,875 total amylase tests), 861 (10\%) were borderline (9\% of total lipase tests and $11 \%$ of total amylase tests), and 7,579 (86\%) were normal (87\% of total lipase tests and $85 \%$ of total amylase tests).

\section{Superfluous vs Questionably Superfluous vs Nonsuperfluous Tests}

As shown in Figure 1, of the 8,801 tests, 3,996 (45\%) were superfluous (6\% of total lipase tests and $96 \%$ of total amylase tests), 787 (9\%) were questionably superfluous (15\% of total lipase tests and $2 \%$ of total amylase tests), and 4,018 $(46 \%)$ were nonsuperfluous (80\% of total lipase tests and $2 \%$ of total amylase tests).

Nonsuperfluous testing was less frequent $(P<0.0001)$ in the ICU/stepdown unit (22\% of 748 tests) than in the ED (54\% of 6,000 tests) and in other settings (31\% of 2,053 tests).

\section{Diagnostic Amylase Tests With Nondiagnostic Lipase Tests}

Of the 3,545 amylase tests obtained simultaneously with normal or borderline lipase tests, $21(0.6 \%)$ were diagnostic (Figure 2A). Eighteen of the 21 diagnostic amylase tests were obtained with normal lipase results and 3 with borderline lipase results (all $>1,000 \mathrm{U} / \mathrm{L}$ ). 


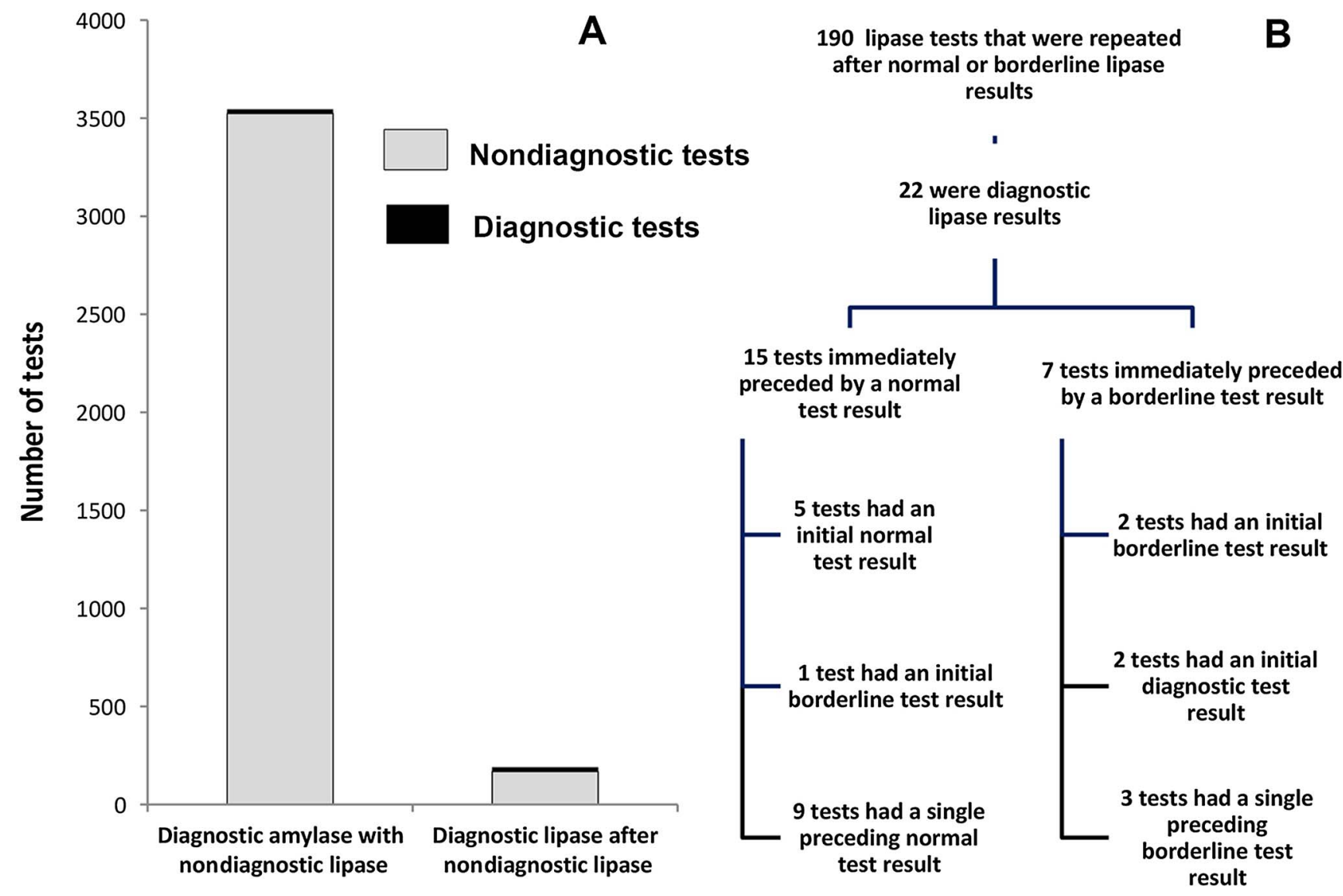

Figure 2. A. Diagnostic amylase tests with and diagnostic lipase tests after nondiagnostic lipase tests. The bars represent the number of tests ordered during a 6-month period. B. Diagram depicts the characteristics of lipase tests preceding diagnostic ones.

Seven of the 21 diagnostic amylase tests were obtained in the ICU/stepdown units, 10 in the ED, 3 in the regular floor, and 1 in the endoscopy suite.

\section{Diagnostic Lipase Results After Same-Clinical- Encounter Normal or Borderline Results}

Of the 190 lipase tests that were repeated after normal or borderline lipase results, 22 (12\%) were diagnostic (Figures $2 \mathrm{~A}$ and $2 \mathrm{~B}$ ). Fifteen of the 22 diagnostic lipase tests were immediately preceded by normal test results and 7 by borderline test results (Figure 2B).

\section{DISCUSSION}

In 2009 alone, the estimated waste of healthcare expenditure was almost $\$ 750$ billion. A large proportion of this waste was attributed to unnecessary services-expenditures that providers can directly avoid by changing their practice. Consequently, several healthcare organizations have implemented measures to reduce waste and incorporate highvalue, cost-effective care into clinical practice. ${ }^{31}$

The diagnosis of AP can often be established by clinical symptoms and laboratory testing without the need for imaging. Although none of the current available biochemical markers can be considered ideal, serum amylase and lipase are the most commonly used, and serum lipase alone is the preferred test for diagnosing AP.
Consistent with previous studies, ${ }^{22-25}$ we found that $45 \%$ of serum amylase and lipase tests were superfluous. Even with a conservative cost estimation of $\$ 50$ per test, eliminating superfluous amylase and lipase tests could result in a cost saving of $\$ 199,800$ during a 6 -month period. Another $\$ 39,350$ could be potentially saved if one considers the questionably superfluous tests as well.

Almost all (96\%) of the 3,875 amylase tests in this study were superfluous compared to only $6 \%$ of the lipase tests, indicating that cost reduction efforts should be focused on amylase ordering. On the other hand, 6,000 (68\%) of the total 8,801 amylase and lipase tests were obtained in the ED and $54 \%$ (significantly higher than other locations) of them were superfluous, suggesting that the ED would be a good location to target.

As stated earlier, several studies have demonstrated that the combination of amylase and lipase testing for diagnosing AP is not better than lipase testing alone.,12-24 Consistently, our study showed that of 3,545 simultaneous amylase and lipase tests with normal or borderline lipase results, only $0.6 \%$ of the amylase results were diagnostic of AP.

Because we did not have clinical data, we could not establish whether these amylase tests were false positive or true positive. Amylase tests are known to be nonspecific and to be elevated in the setting of nonpancreatic diseases, metabolic disturbances, and after endoscopic retrograde 
cholangiopancreatography (ERCP). ${ }^{1,6}$ Thus, the true positive rate of diagnostic amylase tests in the face of nondiagnostic lipase tests should be extremely small.

The clinical utility of repeating amylase and/or lipase tests after normal or borderline results is not known. In our study, $9 \%$ of the 8,801 amylase and lipase tests fell in this questionably superfluous category. Interestingly, of the 190 lipase tests that were repeated after normal or borderline lipase results, $12 \%$ were diagnostic of AP. Again, because we did not have clinical data, whether some or all these diagnosticafter-negative results were attributable to premature initial testing or new pancreatic insult such as sepsis, shock, or ERCP is not clear.

An important note is that our results are based on data collected at one teaching hospital during a selected 6-month period before implementing a quality improvement intervention; consequently, the results may not apply to other settings.

\section{CONCLUSION}

The number of superfluous amylase tests (performed simultaneously with lipase tests or repeated after diagnostic results) and superfluous lipase tests (repeated after diagnostic results) during a 6-month period in a teaching hospital was substantial, suggesting significant potential for reducing healthcare costs without compromising the quality of care when evaluating patients for AP. More studies are required to examine the clinical utility of repeating amylase and lipase tests after same-clinical-encounter, normal, or borderline results.

\section{ACKNOWLEDGMENTS}

The authors have no financial or proprietary interest in the subject matter of this article. Part of the manuscript was submitted as an abstract for consideration as a poster presentation at the American College of Gastroenterology 2018 Annual Meeting.

The completion of this manuscript could not have been possible without the assistance of Muhammad M. Hammami, $M D, P h D, F A C P, F A C E$. His contribution is sincerely appreciated and gratefully acknowledged.

\section{REFERENCES}

1. Tenner S, Baillie J, DeWitt J, Vege SS; American College of Gastroenterology. American College of Gastroenterology guideline: management of acute pancreatitis. Am J Gastroenterol. 2013 Sept;108(9):1400-1415. doi: 10.1038/ajg.2013.218.

2. Spechler SJ, Dalton JW, Robbins AH, et al. Prevalence of normal serum amylase levels in patients with acute alcoholic pancreatitis. Dig Dis Sci. 1983 Oct;28(10):865-869.

3. Clavien PA, Robert J, Meyer P, et al. Acute pancreatitis and normoamylasemia. Not an uncommon combination. Ann Surg. 1989 Nov;210(5):614-620.

4. Toskes PP. Hyperlipidemic pancreatitis. Gastroenterol Clin North Am. 1990 Dec;19(4):783-791.

5. Winslet M, Hall C, London NJ, Neoptolemos JP. Relation of diagnostic serum amylase levels to aetiology and severity of acute pancreatitis. Gut. 1992 Jul;33(7):982-986.

6. Yadav D, Agarwal N, Pitchumoni CS. A critical evaluation of laboratory tests in acute pancreatitis. Am J Gastroenterol. 2002 Jun;97(6):1309-1318.
7. Gullo L. Familial pancreatic hyperenzymemia. Pancreas. 2000 Mar;20(2):158-160.

8. Heikius B, Niemelä S, Lehtola J, Karttunen TJ. Elevated pancreatic enzymes in inflammatory bowel disease are associated with extensive disease. Am J Gastroenterol. 1999 Apr;94(4):1062-1069.

9. Lott JA, Speicher CE, Nemesánszky E. Is serum amylase an obsolete test in the diagnosis of pancreatitis? Arch Pathol Lab Med. 1985 Apr;109(4):314-315.

10. Steinberg W, DeVries JH, Wadden $T A$, Jensen CB, Svendsen CB, Rosenstock J. Longitudinal monitoring of lipase and amylase in adults with type 2 diabetes and obesity: evidence from two phase 3 randomized clinical trials with the once-daily GLP-1 analog liraglutide. Gastroenterol. 2012 May;142(5):S850-S851.

11. Shah AM, Eddi R, Kothari ST, Maksoud C, DiGiacomo WS, Baddoura W. Acute pancreatitis with normal serum lipase: a case series. JOP. 2010 Jul 5;11(4):369-372.

12. Thomson HJ, Obekpa PO, Smith AN, Brydon WG. Diagnosis of acute pancreatitis: a proposed sequence of biochemical investigation. Scand J Gastroenterol. 1987 Aug;22(6):719-724.

13. Apple F, Benson P, Preese L, Eastep S, Bilodeau L, Heiler G. Lipase and pancreatic amylase activities in tissues and in patients with hyperamylasemia. Am J Clin Pathol. 1991 Nov;96(5):610-614.

14. Gumaste VV, Roditis N, Mehta D, Dave PB. Serum lipase levels in nonpancreatic abdominal pain versus acute pancreatitis. Am J Gastroenterol. 1993 Dec;88(12):2051-2055.

15. Malka D, Rosa-Hézode I. Positive and etiological diagnosis of acute pancreatitis [in French]. Gastroenterol Clin Biol. 2001 Jan;25(1 Suppl):1S153-1S168.

16. Working Party of the British Society of Gastroenterology; Association of Surgeons of Great Britain and Ireland; Pancreatic Society of Great Britain and Ireland; Association of Upper Gl Surgeons of Great Britain and Ireland. UK guidelines for the management of acute pancreatitis. Gut. 2005 May;54 Suppl 3:iii1-9.

17. Kolars JC, Ellis CJ, Levitt MD. Comparison of serum amylase pancreatic isoamylase and lipase in patients with hyperamylasemia. Dig Dis Sci. 1984 Apr;29(4):289-293.

18. Ventrucci M, Pezzilli R, Naldoni P, Montone L, Gullo L. A rapid assay for serum immunoreactive lipase as a screening test for acute pancreatitis. Pancreas. 1986;1(4):320-323.

19. Keim V, Teich N, Fiedler F, Hartig W, Thiele G, Mössner J. A comparison of lipase and amylase in the diagnosis of acute pancreatitis in patients with abdominal pain. Pancreas. 1998 Jan;16(1):45-49.

20. Werner $\mathrm{H}$, Steinberg WM, Pauley $\mathrm{C}$. Strategic use of individual and combined enzyme indicators for acute pancreatitis analyzed by receiver-operator characteristics. Clin Chem. 1989 Jun;35(6):967-971.

21. Smith RC, Southwell-Keely J, Chesher D. Should serum pancreatic lipase replace serum amylase as a biomarker of acute pancreatitis? ANZ J Surg. 2005 Jun;75(6):399-404.

22. Vissers RJ, Abu-Laban RB, McHugh DF. Amylase and lipase in the emergency department evaluation of acute pancreatitis. $J$ Emerg Med. 1999 Nov-Dec;17(6):1027-1037.

23. Gomez D, Addison A, De Rosa A, Brooks A, Cameron IC. Retrospective study of patients with acute pancreatitis: is serum amylase still required? BMJ Open. 2012 Sept 21;2(5). doi: 10.1136/bmjopen-2012-001471.

24. Hofmeyr S, Meyer C, Warren BL. Serum lipase should be the laboratory test of choice for suspected acute pancreatitis. $S$ Afr J Surg. 2014 Aug 8;52(3):72-75. doi: 10.7196/sajs.2003.

25. Akhtar A, Sarode R, Agrawal D. Measuring both serum amylase and lipase for acute pancreatitis lowers quality and raises cost. 
Cleve Clin J Med. 2017 Sept;84(9):670-672. doi: $10.3949 /$ ccjm.84a.16103.

26. Yegneswaran B, Pitchumoni CS. When should serum amylase and lipase levels be repeated in a patient with acute pancreatitis? Cleve Clin J Med. 2010 Apr;77(4):230-231. doi: $10.3949 /$ ccjm.77a.09083.

27. Kim YS, Lee BS, Kim SH, Seong JK, Jeong HY, Lee HY. Is there correlation between pancreatic enzyme and radiological severity in acute pancreatitis? World J Gastroenterol. 2008 Apr 21;14(15):2401-2405.

28. Lankisch PG, Burchard-Reckert S, Lehnick D. Underestimation of acute pancreatitis: patients with only a small increase in amylase/lipase levels can also have or develop severe acute pancreatitis. Gut. 1999 Apr;44(4):542-544.
29. Banks PA, Freeman ML; Practice Parameters Committee of the American College of Gastroenterology. Practice guidelines in acute pancreatitis. Am J Gastroenterol. 2006 Oct;101(10):2379-2400.

30. Jasdanwala S, Babyatsky M. A critical evaluation of serum lipase and amylase as diagnostic tests for acute pancreatitis. Integr Mol Med. 2015;2(3):189-195. doi: 10.15761/IMM.1000137.

31. Smith M, Saunders R, Stuckhardt L, McGinnis JM, eds. Best Care at Lower Cost: The Path to Continuously Learning Health Care in America. Washington, DC: The National Academies Press; 2013. www.nap.edu/catalog/13444/best-care-at-lower-cost-the-pathto-continuously-learning. Accessed April 9, 2019.

This article meets the Accreditation Council for Graduate Medical Education and the American Board of Medical Specialties Maintenance of Certification competencies for Patient Care, Medical Knowledge, and Practice-Based Learning and Improvement. 